\title{
African Women, the Vision of Equality and the Quest for Empowerment: Addressing Inequalities at the Heart of the Post-2015 Development Agenda and the Future
}

\author{
Ani Casimir ${ }^{1}$, Ome Emmanuel ${ }^{2}$, Maudline Okpara ${ }^{3}$ \\ ${ }^{1}$ Department of Philosophy, Institute of African Studies/Political Science, \\ University of Nigeria, Nsukka, Nigeria \\ ${ }^{2}$ Department of Philosophy, University of Nigeria, Nsukka, Nigeria \\ ${ }^{3}$ School of General Studies, University of Nigeria, Enugu Campus, Enugu, Nigeria \\ Email: cepperngo@yahoo.com,drommema@yahoo.com, maudlineokpara@gmail.com \\ Received January $7^{\text {th }}, 2013$; revised February $7^{\text {th }}, 2013$; accepted February $17^{\text {th }}, 2013$
}

Copyright (c) 2013 Ani Casimir et al. This is an open access article distributed under the Creative Commons Attribution License, which permits unrestricted use, distribution, and reproduction in any medium, provided the original work is properly cited.

\begin{abstract}
The history of women has been defined by a world enmeshed in woes, frustration, oppression, maltreatment and inequalities. Feminism as a philosophy of change sought to fight, end and change this woeful scenario of women that denied their self respect, dignity and led to a loss of self confidence. Fundamentally, feminist philosophy sought for explanations and justifications why women were denied a voice and why they were historically not treated as coequals of men. The basis of inequality is historically rooted in cultural and philosophical falsities that were not evidenced based but were used to justify oppression against women. The Universal Declaration of human rights gave women and the world the platform that empowered them with rights and led to fresh processes that sought to end oppression and their underdevelopment inspired by inequality, iniquities, denial of opportunities for growth and empowerment. The millennium development goal of ending inequality and oppression against women should achieve equality and women's empowerment in Africa. Since the declaration of the MDGS, considerable gains had been made in Africa but challenges and problems are still identified in the areas of cultural inequality complicated by the weakness of the major governance institutions and corruption. Other challenges centre on women's lack of genuine empowerment, violence against women, trafficking in women, denial of human rights, lack of participation in policy and governance. Since empowerment is the key to achieving mainstreaming and gender equality, this paper seeks to redefine the concept of empowering women as the platform to ending inequality, social injustice and achieving equality in the context of the unique challenges of underdevelopment facing Africa. It will identify the policy implications of establishing empowerment structures that address multiple challenges facing gender inequality and how these structures will assist in building the necessary feminine human resources that will make women as partners of sustainable growth and development after 2015.
\end{abstract}

Keywords: Gender Equality; Women Empowerment; Policy Participation; Post MDG Africa

\section{Research Methodology}

The paper will use the gender analytical framework to examine and analyze the situation of women and how far the MDGS and other policy actions by government have served to either empower or dis-empower women in Africa using select examples from Nigeria, Uganda and other parts of Africa. The theoretical framework of empowerment as applied by Addanna Madu (2010) and Jo Rowland (1997) with the African Union's report documents on condition of women in Africa will be used as primary theoretical models with data drawn from the United Nations for women. An examination of the secondary sources drawn from NGOS and Government women ministries will complement the data sources used to support the new empowerment paradigm applied by the article. The central focus and thrust of this research methodology are that when the reconstructed cultural cosmology and ontology combined with asso- ciated core gender values free women in Africa from the thralldom of cultural patriarchy (Ani, 2013: p. 20) they can seamlessly participate in development planning, programming and implementation and become genuinely empowered in the real empirical sense of the word as applied by Oxfam's feminist writer Rowland Jo and Addanna Madu of the Rights Initiative for Justice.

\section{Introduction}

Women in Africa need a bottom-up, grassroots and participatory communication for development model to be truly empowered through governance and development policy. The challenge of clearing all obstacles that confront and weaken women's participation in policy and decision making processes of development planning in Africa is the single most potent factor that stands between them and genuine empowerment; 
and it is also the biggest variable that will account for sustainability in post 2015 gender equality successful drive and achievement (Ani, 2013: p. 13).

\section{The Challenge of Policy Participation}

Empowerment through policy will positively affect and catalyze women to participate and benefit from the policy and civil society initiatives of development programs because what happens in the other areas of the MDG goals will have policy and social implications for women's search for empowerment, and, hence, equality, in the continent. Empowerment will elevate and support women with the philosophy and the capacity to achieve national development objectives in real terms through human rights based approach. In the realm of genuine empowerment, women need to participate in identifying their needs, problems, challenges and contribute in generating sustainable solutions to their predicament. This will help women to move from mere project participation into the realm of policy making. The state, civil society and the economic structures all shape and constrain women's lives in Africa as stakeholders in formulating, implementing, monitoring and evaluating policies aimed at empowering women.

It is important that women of Africa are allowed to participate in redefining the processes and strategies of empowerment schema to achieve sustainability after 2015 to scale up the tempo of gender mainstreaming and equality.

\section{Cultural Challenges of Empowerment}

The achievement of policy and governance participation by women will help them to confront also the cultural challenges inherited from the past and the structural impediments to policy integration and mainstreaming in the work place and in their homes to redress the structures of inequality in the development process. To achieve this will mean empanelling policy, programs and institutions that will lead to the achievement of genuine empowerment in Africa. Miguel Szeleky, discussing the challenges facing the achievement of the Millennium Development Goal on promoting gender equality and empowerment of women, says that the third MDG "challenges cultural norms and traditions and requires deep changes in day-to-day individual behaviour and practices, which are normally regarded as a 'private matter.' This feature is also the main challenge for implementation” (World Bank, 2007). He goes on to specify:

On the one hand, changing the role of women and empowering them modifies household arrangements substantially, and in many cases this is not regarded as a desirable change for specific family members. On the other hand, identifying effective public policies for promoting gender equality is especially difficult in the context of deeply entrenched traditions and cultural patterns... Moreover, the enactment of specific policies may generate intense resistance from different sectors of society (Ibid).

An unnamed MA student at An MA candidate-International development studies, Dalhousie university in his term paper "Human Rights, Gender and Development" supports this negative cultural role that inhibits women empowerment and questions if development can take place in societies where the human rights of women are systematically abused? He gives further elaboration thus:
In other, words, the achievement of gender equality in developing countries is fundamentally prevented by cultural and traditional norms. And since these norms are handed down from generation to generation, and are deeply embedded in our daily practices, measures such as legislative reforms of government policies to expand the coverage of services for women cannot have long-term effectiveness in reaching gender parity, and indeed, as argued by Szekely, may have inverse effects on women. Although such measures are a necessary condition, they are not sufficient. What can be most effective in the long run is to challenge long-held beliefs and traditions about the role of women in society: the value of their work in the household, their ability to be productive, and the provision of private assets to vitalize this productivity.

\section{The Problems Facing Women in Africa and Making the Paradigm of Empowerment to Work in the 21st Century}

The problems of the African woman are in the same breath quite like and unlike the global problems of women qua women every where. The problems faced today in Africa are fundamentally and uniquely African in terms of empowerment, disempowerment, culture and its unique historical praxis. The European woman of today has surpassed the cultural barriers of acceptance, respect and recognition by her society. She has moved to the stage of empowerment at the level of decision making, policy making and power sharing both in the private and public sectors of the European society. However, the majority of African women are still tied down and burdened by cultural ignorance, selfish institutional patriarchy, prejudice and discrimination from a patently paternalistic cultural heritage that fail to give the average woman a pride of place. This cultural hubris creates enormous disempowerment linkages and structures in the homes, villages, religions and the professions that effectively close the cultural door of freedom on her and her aspirations, consistently prevents her from joining and taking part in the decision making processes of African society. For her to move into the policy and decision making structures of the modern African state and be fully integrated in governance she will need to be fully liberated from the realm of cultural disempowerment. This liberation will make her untapped energy, resources, abilities and competency framework to be available to be placed at the portals of service for African development. The great potential synergy and collateral abilities of African women remained chained, untapped and unexploited despite the aspirations and goals of the United Nations Millennium Declaration as documented under the item three of the Millennium Development Goals (2015).

The challenges of cultural disempowerment prevent more African women from being unburdened and constitute a significant her efforts to be part of the continent's development planning. The cultural environment debilitates her and effectively stops her from contributing towards the collective achievement of the socio-economic goals of development. Culture stops her on her tracks from being considered as a partnership factor in planning for development. The injustice in the status of those who find their way, after a hard won struggle, inside arena of planning and governance are presented when they are deliberately prevented from enjoying equal pay for equal work as recorded by the men. The non-reception of her massive con- 
tributions to the domestic economy of African families is part of the fallout and outcome of the her cultural travails in Africa.

The African woman is culturally disempowered and needed to be culturally empowered to be available for socio-economic and governance development. The cultural concepts and structures that disempowered her needed to be fully researched clarified and reconstructed in a manner that empowers her mind with the right education, tools and disabuses the minds of the abusive traditions setup by the male-folk who had oppressed and discriminated against her for centuries. The reasons and factors why the gender-oriented goal three of the MDGS could not be wholesomely achieved in Africa is because of the failure to factor into state the programs and goals the culturally and socially limiting variables that force the African women into submission, denying partnership status to women as equals in development. The sustainable goal of achieving gender quality and women's empowerment in Africa would become a reality when these cultural problems are identified as factors for planning and programming of a post 2015 agenda. The problems facing women in the African socio-cultural environment had been variously researched and identified: women in Africa suffer violence, discrimination and oppression triggered by limiting cultural factors that emanate from prejudices and biases within micro cultures in the continent. The psychosomatic negative impact of the constructed myths/customs from this limiting socio-cultural environment is such that even the women start to believing that their limited capacities, inabilities and weaknesses to self realization and achievement are God ordained. In other words, their thinking and false gender consciousness engendered by historical oppression against them is that "our culture must be right". This false consciousness has become the self-credo of most oppressed, violated and discriminated women, who, most of the time are afraid of crying out of their shells, refusing to accept the need to challenge the status quo and partnering with willing males to deconstruct, reconstruct and construct a new cultural set of values, mores and customs that would engender equality, end violence against women and empower them in every stage of the decision making process of the African state and local communities.

In Africa, these distinctive patterns of traditions and their limiting ideas, beliefs and norms are embedded in the African way of life that disempowered women personally and collectively. They determine the cultural group's gender ideologies that define the rights, responsibilities, dos and donts, appropriate, inappropriate behavior for either men or women. These gender behavior template determine primary access, mode of access, length of access and control over resources and the decision making process for every part of Africa. The African gender empowerment template has favored men and paternalistically disfavored women for centuries. The African paternal grind over women led to the creation of customary laws that created unequal/gender relations that have reinforced male domination, recreated the myth of feminine inferiority and made impossible the promotion of gender equality and the empowerment of women as effective ways to ending poverty, hunger, disease and to stimulate sustainable development. While gender equality and empowerment of women are central to the achievement of all the goals set by international and national governments for women, empowerment in real and sustainable terms is the very key to achieving gender equality, gender mainstreaming and ending poverty for women and sustainable development in a post 2015 African context. Under the
Beijing Conference initiative, 12 problem areas were identified as crucial in achieving genuine empowerment of women.

The 12 areas of women empowerment we should focus upon and be concerned with (Beijing, 1995) included poverty, education, health, ending violence, armed conflict, economic disparity, power sharing, institutions, human rights, mass media, environment and the "girl-child" education. In addition to the Beijing 12, it relevant to this discourse to add "culture" as the 13th area of concern and focus, in accordance with the theoretical model promoted by this research work. This because culture forms the historical motif under which women had been both negatively and positively disempowered under an unfavorable gender ideology that affects and determines their gender challenges, needs and aspirations. The sustainable empowerment of women in Africa must begin and end in culture where paternalism has been seen as a factor of disempowerment. The roots of women's disempowerment must be sought in the cultural norms and mores of various African traditional societies that have denied them equal respect, status, reward and recognition as partners in progress.

Culture will define the nature, context measure of empowerment tools programs and education that will reposition women in a post 2015 context in Africa. The 12 critical areas drawn up under the Beijing platform of action (1995) must emanate and draw their relevancy and potency from the nature of the cultural challenges facing the African woman in her environment. The non inclusion, investigation and reconstruction of the missing cultural gaps in the agenda of the millennium Development Goals (MDGs), other international, regional and national programs required for women's empowerment have accounted for the non-realization and non-achievement of its goals. To draw up a workable and gender sensitive post 2015 programs for women in Africa which will effectively empower them in a sustainable sense, one must factor into the equation and agenda the forces of culture and social ideology that have severed to undermine women's empowerment and drive for equality.

The notion of clearing the cobwebs of gender bias in culture frees women for genuine empowerment programs and processes. Empowerment of women in history by several organizations and programs had been questioned and challenged as programs that claim public acclaim without making any impact in the lives of the targeted group of women. This claim is buttressed mostly by the rhetoric that emanates from government Houses where, the governments pose as champions of women empowerment with huge expenditure profile supposedly meant to empower women but, which in fact, end up inside the private pockets of Africa's First Ladies (wives of the Heads of Government). In her work, “questioning empowerment”, J. O. Rowlands (1997) re-examined the traditional concepts of power and empowerment as it relates to social change and women development. Quoting Kabeer (1994) Row land observes that if there is a single most important lesson for feminists to learn from the past decades of development, it is that the practical will which addresses women's strategic gender interests is contigent on women themselves organizing to demand and promote change. Row land went ahead in her theoretical framework to provide a definition of empowerment especially how it can be used in relation to women with the use of a gender and development analysis. Most importantly, it relates how theoretical and practical dimensions of empowerment offer us the leverage needed under the 2015 context that can do with a lot of disciplined, 
precise and useful tools for women activists, gender activism, planning, monitoring and evaluation of dynamic processes and programs targeted at achieving gender balance and mainstreaming. In this context, the empowerment grid as fostered by Row lands (p. 4) has led to a new window of understanding the concept of women empowerment and its related terms:

Terms such as participation, consultation and partnership began to enter the development vocabulary, reflecting the increased importance being given by many development organizations to an enabling approach which respects people's abilities to identify and express their own needs and priorities. It also indicates a commitment to change practices based on neo-colonial attitudes that perpetuate relations of inequality. The term empowerment has also arisen within this context.

Allowing people to integrated or to be involved in their own development became the credo of empowerment that later crept into the literature of women and gender studies. Esther Boserup (1970) came up with her ground breaking work known as "women in development" (WID) and attacked the paternalistic development theories which completely ignored women as primary producers but saw them as receivers of welfare and patronage. WID sought to include women components in wider development projects and programs so as to achieve "the integration of women into development as an efficient approach that utilized women's productive potential”. However, this approach was criticized since it failed to question "the existing social structures or causes of women's subordination, focusing instead on women's role in production (Row land: 5). In its place emerged the concept of "gender and development" (GAD), an approach concerned with the dynamics of gender relations. Gender relations is seen as vital to the achievement of the different goals of development since it highlights the power relations between men and women with focus on situations of subordination suffered by women in every society. Gender relations yield to gender analysis to expose the relation of empowerment and disempowerment within the socio-cultural, economic, political and state constructs of every society. Every culture exposes its unique cultured challenges, problems and needs in the area of empowerment. The notion of empowerment of women has increasingly been seen as the anti-dote and panacea to the historical challenges faced by women as part of the gender and development debate.

The "WID" GAD and other concepts of empowerment have flowed into a wonderful global stream that have energized and synergized a genuinine empowerment model that had proven to be useful to the United Nations and acceptable worldwide, notwithstanding that factoring the culture gaps into the equation will help to establish women' practical and strategic gender interests as well observed by Row land (7):

the focus on empowerment is on the distinction, useful for analysis and planning, between practical and strategic gender interests. Women's practical needs result from their position in society ; that position means that women also have strategic needs, that challenge the gender hierarchies and other mechanisms of subordination. Eliminating male bias and moving women out of the condition of near-universal subordination they still currently occupy will not be achieved by tinkering with conditions of employment or national accounting procedures; it will re- quire cultural, economic and political changes. The power dynamics between men and women will have to be addressed.

The cultural, practical and strategic experiences and needs of women in Africa should be focused upon elevating women at the grassroots village level through the urban communities for effective ways of supporting women, sustaining their self help efforts to define their needs and empowering them to make changes within their cultural milieu. Thus we can say that empowerment implies "some unspecified recognition of the need for changes in the distribution of power's" (Rowland ibid). In furtherance of this idea, Chambers (1989) discusses "enabling and empowering poor clients and the need to "see that they know their rights and have power to demand them, enabling them to ensure quality of service and access". The women empowerment failure in the development equation in Africa comes from "a failure to define and explore the practical details of how empowerment can be achieved as a tool of analysis or as part of a strategy for change" (Rowland: 8). The kind of empowerment needed by African women revolves around the personal and collective approaches as conceived by Jo Row lands both kinds enable women to challenge basic socio-cultural inhibitions and attitudes that limit their participation and contribution in developmental matters of the society. For both personal and collective empowerment, there are a set of core processes, core values, encouraging and inhibiting factors that may contribute to or mar changes in women's lifestyles as identified by Row land (110-128).

\section{Personal Empowerment}

According to Row lands (1997: p. 15), personal empowerment means "developing a sense of self and individual confidence and capacity, and undoing the effects of internalized oppression”. Any empowerment program meant for sustainable development in a post 2015 development scheme in Africa must seek to empower the individual woman to give her a sense of freedom from cultural, socio-economic and political oppression. Till now, this has not been the case in Africa. Personal empowerment of the African woman will lead to collective empowerment and create relational freedom that will establish gender equality in the Continent.

\section{Collective Empowerment}

Equally illuminating is Rowlands' paradigm shifting definition of collective empowerment framework for women in the real sense which relates practically and pragmatically in changing the condition of the grassroots women groups at the village level in Africa. According to her, this will enhance the possibility of international programs being institutionalized and leading to huge positive impacts in the lives of women:

Where individuals work together to achieve a more extensive impact than each could have done which includes involvement in political structures, but might also cover collective action based on cooperation rather than competition. Collective action here may be locally focused-for example, groups acting at village or neighborhood levelor be more institutionalized, such as the activities of national networks or the formal procedures of the United Nations.

Personal empowerment supports collective empowerment in 
a cooperative sense since it helps women to individually and collectively to understand their situation and to move from insight, education and mobilization to action to change the situation. This enables women to work on their relationships and understand the power dynamics of the situation and seek to change the oppressive power dynamics that oppress them and infringe on their rights. This particular angle given to the meaning of collective empowerment has been well explained by Mc Whirter (1991:222-227) as: "the process by which people, organizations or groups who are powerless (a) become aware of the power dynamics at work in their life context, (b) develop the skills and capacity for gaining some reasonable control over their lives, (c) exercise this control without infringing upon the rights of others and (d) support the empowerment of others in the community”. Personal and collective empowerment of the African woman will lead to relational empowerment in the context of the existing gender relations in Africa and help her to participate in the decision making processes, structures and institutions of development. This is the sense in which women empowerment will lead to sustainable development and the achievement of gender equality in the real sense in Africa. This brief review of the framework of empowerment demonstrates that the concept could be of value when it comes to planning, formulation and programming for special development interventions meant for the continent at the international, regional, national or local government levels. This view supports women getting involved in decisions on programs meant for not only their own good but also meant for the good of the entire continent.

\section{Examining the MDG Actions Taken to Redress Gender Inequality and Empower Women in Africa}

When we look at actions taken by African countries to comply and commit moral and material resources to global commitments on empowering women, we discover that so far, with regards to the protocol on Elimination of all forms of Discrimination Against Women (CEDAW), 51 out of 53 African Member States have ratified the Convention and 17 have signed the Optional Protocol. On the general response to regional treaties such as the African Women's Protocol a total number of 25 countries have ratified the Protocol, while an additional number of 23 have signed. These countries are: Angola, Benin, Burkina Faso, Cape Verde, Comoros, Djibouti, Gambia, Ghana, Libya, Lesotho, Liberia, Mali, Malawi, Mauritania, Mozambique, Namibia, Nigeria, Rwanda, South Africa, Senegal, Seychelles, Tanzania, Togo, Zambia and Zimbabwe. Countries which have only signed are Algeria, Burundi, Cameroon, Central African Republic, Chad, Cote d'Ivoire, Congo, Democratic Republic of Congo, Equatorial Guinea, Ethiopia, Gabon, Guinea Bissau, Guinea, Kenya, Madagascar, Mauritius, Niger, Sahrawi Arab Democratic Republic, Sierra Leone, Somalia, Sudan, Swaziland and Uganda. Those which have not taken any action at all are: Botswana, Egypt, Eritrea, Sao Tome and Principe and Tunisia. Sixteen (16) Member States have reported on the implementation of the SDGEA, namely: Algeria, Burundi, Burkina Faso, Cameroon, Côte d'Ivoire, Ethiopia, Ghana, Lesotho, Mali, Mauritius, Namibia, Nigeria, Rwanda, Senegal, South Africa and Tunisia.

In the first place, constitutional domestication of international gender sensitive treaties is central to the achievement of the MDG equality protocol and the achievement of the goal of sustainable development in Africa. This is because the adoption of state constitutions that promote gender equality in Africa, makes it possible for states in Africa to institutionalize gender equality and the empowerment of women as national constitutions guarantee equality before the law and non-discrimination, while directing their respective state Governments to embark upon affirmative action measures to correct pre-existing cultural and socio-economic and political imbalances. These imbalances could only be addressed as they occur between males and females in their daily societal engagements. But while most governments have adopted constitutions that take on broader gender equality and empowerment, only five countries-Benin (1990), Ghana (1992), Ethiopia (1994) and Malawi (2006) and Uganda (1995) - have made progress in real terms. For example, Article 35 of the constitution of Ethiopia recognizes and states as follows:

The historical legacy of inequality and discrimination suffered by women in Ethiopia taken into account, women, in order to remedy this legacy, are entitled to affirmative measures. The purpose of such measures shall be to provide special attention to women so as to enable them to compete and participate on the basis of equality with men in political, social and economic life as well as in public and private institutions.

However, the establishment of institutional mechanisms and gender structures in African countries are also vital to the realization of women empowerment and the achievement of sustainable development in a post 2015. When we examine actions and progress made in this area, we find a dismal record too. Though efforts had been made by African governments to structure gender mainstreaming into national development and poverty reduction strategies data segregation and lack of capacity building to realize these efforts had been poor and uncoordinated between the different sectors and levels of Government within a particular country. The example of Nigeria is noteworthy where there are no available data on indicators on progress, gaps identified and challenges faced in institutionalizing women empowerment initiatives in the budgets of the different Ministries (Adanna, 2010).

Another area where actions had been taken, albeit by a few countries, is mainstreaming women budget matters and needs into the annual budgets of African countries. This gender responsiveness in resource allocation enables women to participate in development activities by accessing public resources and getting equal pay for equal work. Good gender budget initiatives and policies have been identified in South Africa, Tanzania, Uganda, Rwanda, Mauritius, Senegal, Ghana and Morocco. However paucity of human and financial resources needed to build capacity of the institutions to correctly formulate, implement and monitor the budgets remain a huge challenge for Governments in Africa. Again, lack of involvement of women in the budgeting process keeps sabotaging the real objectives of empowerment.

In the area of initiating legislative reforms to take care of socio-cultural and legal constraints to equality in Africa, some African countries have taken substantial measures while the majority still lack behind. Article 13 of the Protocol to the African Charter on Human and People's Rights on the rights of women in Africa states that Parties shall adopt and enforce legislative and other measures to guarantee women equal opportunities in work and career advancement and other eco- 
nomic opportunities. However although the legal framework for women's equal rights to land is in place, structural, cultural and economic constraints are still likely to limit women's access to and control of land (Akinyi-Nzioki, 2006). In Nigeria, some states such as Enugu and Lagos states have enacted the widowhood bills to guard against culturally motivated violence and oppression of widows and women, the other 34 states are still prevaricating whether or when to do so in their states. As these constraints exist to sabotage the empowerment of women and the achievement of equality in Africa we should also recognize that the lack of good governance that could have facilitated the realization of these gendered goals had been responsible for the slow process recorded by many countries on gender equality on the continent.

\section{Policy Actions Taken in the Context of Empowerment and Gender Mainstreaming in Africa}

African countries have in various ways shown commitments to ending gender inequality and disparity in the continent. These commitments have enhanced the empowerment of women through policy actions that demonstrated a regional willingness to redefine the future of women in the continent. These areas of demonstrated commitments are women's rights, addressing violence against women, access to quality education, quality health care, economic opportunities and resources and women agency in formal and informal decision making institutions.

\section{Challenges Faced in Addressing Gender Inequality in Africa}

It is recognized that within the continent that major commitments had been shown by Governments to address inequality in Africa, but they had been not been done in such a way to address the decade-old dis-empowerment of women. Commitments made are not sustainable, not enough to redress the gaps and to empower women in real terms both at the personal and collective levels. As a result, the ratification of both international and regional instruments have not positively resulted in substantial changes in the lives of women, with huge gaps still existing between policy and practice, current practices and international best practices and a prevalence of still to be resolved cultural regime of patriarchy that still believes that women are inferior and second class citizens. There are seventeen obstacles and challenges responsible for this baleful scenario as identified by the report of the sixth session of the African development forum focused upon "achieving gender equality and women's empowerment in Africa” (2008: pp. 26-29):

1) Continued presence of strong cultural and traditional practices constraining progress in achieving gender parity in the areas of public/private/domestic attitudinal discrimination, education, health, access to justice, ownership of land and property, unjust widowhood practices, serial violence and rape of women;

2) Lack of ratification of the instruments that promote gender equality;

3) Ineffective institutional and policy implementation mechanisms;

4) Lack of adequate resources;

5) Lack of enforcement of laws that promote gender equality and lack of knowledge of laws;

6) Lack of full involvement of men and boys;

7) Continued lack of recognition of women's unpaid work;
8) Violation of women's rights;

9) Limited gender equality in decision making and governance;

10) Lack of supportive complementary policies;

11) Inadequate documentation and dissemination of successful practices for replication;

12) Limited role of the media;

13) Lack of sex disaggregated and gender data;

14) Weak monitoring and evaluation of systems.

Recent additional challenges made by the Women Empowerment framework forum (CEPPER, 2012: p. 23) also identified another critical source of gaps in achieving gender equality and empowerment of women in Africa as:

15) Non-involvment of women as fundamental stakeholders in designing programs meant for their welfare, with the result that others define what they need and how it will be of benefit to them;

16) Non use of development communication tools as a participatory governance process when engaging women;

17) Conflict of interests between educated urban women elites and their uneducated rural grassroots counterparts;

18) Political window dressing on gender equality that leads only to the propaganda on only paper work;

19) Endemic corruption in African states;

20) Non design of proper strategic agendas for the First Lady forums used only to corner resources of state by the wives of state presidents but not to empower women or effect any gender policy;

21) Non-integration of different ministerial programs with gender and poverty reduction filters.

\section{Recommendations to Achieve a Post 2015 \\ Empowerment Framework and Gender Equality in Africa-Need for a Human Rights Based Development Approach}

My entire recommendations will revolve around gender mainstreaming and empowerment of women in Africa to achieve sustainable gender equality and development in the continent based upon the following suggestions:

\section{Domestication of the International and Regional Gender Policy Laws and Documents}

The domestication of these international gender instruments and laws will empower the states and civil society organizations to implement and protect women and ensure budgetary and statutory provisions for them within the context of national laws of African governments. Most governments are yet to do this domestication and it is huge problem that creates a contradiction between international, regional and national gender policy laws. This domestication will provide governments with a roadmap to provide sustainable interventions with participatory contents and programs what empower women both at the urban and rural areas, making it possible for them to legally make claims against violations.

\section{Gender Based Legal Reforms in the State Legislatures}

States and civil society organizations need to sponsor gender based culture-orientated legal reforms and violence (prohibition) to protect and make specific provisions for women and girls to 
ensure prohibition from all forms of abuse and exploitation in the labor market and the economy.

\section{Advocacy and Provisions for Women in Decision and Policy Levels}

There is need to ensure a state recognized civil society advocacy and provision for increased measurable number of women to be included and involved in decision making and policy making organs of governance at the state and local governance levels. These provisions should be constitution alised and legalized at the national levels. This will achieve, for good measure, positive involvement of women as decision makers and partners in formulating, implementing, monitoring and evaluating policies aimed at achieving human development in the continent. It will, more than anything else, see an increasing ratio and population of women at the cabinet, state houses of assembly, the civil service, local government leadership, and, most importantly, membership of the of boards and parastatals, especially those that have to do with poverty reduction, education and women affairs at the state and national levels in Africa.

\section{Establishment of a Women Forum in Leadership at the Local, State and National Levels}

This will serve as a kind of effective peer review mechanism recognized by the state to benchmark, monitor, evaluate and measure the levels of various state compliance and achievement of international mechanisms as established in such organizations as the United Nations women and the African Action reports on gender equality and women empowerment (2008) and the various action plans on empowerment of women and achievement of gender equality adopted by different states in Africa. For good measure, these periodic for a will be made up women members of parastatals, ministries, educational institutions, women community cooperatives and leaders of civil society groups with gender orientation and mandates within each country. This forum will also convene a periodic gender based summit for women, sponsor a women leadership workshop, set up a women micro-credit centre and organize a political empowerment platform to ensure women's participation and integration in political party and electoral processes at the local, state, and national levels with a pro-active agenda aimed at achieving the ration of women involvement in politics and institution building.

\section{Enactment of Women Equal Opportunities Act at the Level of the Local, State and National Assemblies}

The women equal opportunities act should ensure equal treatment of women in the work place and the achievement of judicial access for women to claim their constitutionally enshrined rights related to all the gender issues that affect them within the socio-economic, cultural and economic spheres of every nation, beginning at the local, state and national governments. African Union regional gender instruments should set a peer review mechanism on gender based equal opportunity review at the national levels that will measure and benchmark the compliance levels by each country in the continent at periodic levels. The level of international and private donor aid to African countries should be determined by the rate of their movement up or down the gender scales of equality in their countries in measurable terms.

\section{Gender Based and Culture Oriented Public Awareness Campaigns}

To address the issues that emanated from cultural patriarchy and oppression against women for which Africa is notorious for, there is need to have a well organized public campaigns targeted at infusing the public consciousness of gender equality and erasing the false consciousness of inferiority which have dis-empowered women and created a sense of inferiority amongst them. This campaign will look into particular cases of injustices against widows, the girl child education, early marriage, religious prejudices, work place discrimination, and various instances of cultural bias aimed at disempowering women and sabotaging all the finer goals of the different international, regional and national instruments aimed at achieving gender equality and empowering women. This will also make women readily available to be mobilized at the different levels of decision and policy making where issues that concern their welfare and existence are determined.

\section{Reforming the Women Affairs Ministries with an Authentic Gender Agenda and Grassroots Strategy}

Most women ministries in Africa are only women oriented in name but not in terms of effective policy goals and strategies that really reflect the participatory contributions of women and the genuine articulation of women's problems and issues of empowerment and achieving gender equality in real terms. This has been one problem that has sabotaged the achievement of women empowerment in the continent since the women affairs ministries are seen as symbolic policy and political posts that are meant to showcase how "gender sensitive" they are without any real policy efforts with the possibility of changing the position and situation of women in the continent. Some are being set to attract international and regional funding from donor agencies and achieve the political and electoral votes of women for selfish critical election motives. Most electoral promises aimed at erecting gender-based development policy and programs are shamelessly abandoned after the elections had been won by the male campaigners for public offices in Africa. A genuine women affairs ministry that has undergone the necessary gender-based reforms in content should mobilize, educate, integrate and empower women in real measurable terms that should achieve gender equality and sustainable development in a post 2015 Africa.

\section{Conclusion}

In conclusion, as a way forward, I will like to recommend the following tested and tried good practices that have worked in some countries such as Ghana, South Africa and Nigeria:

1) Domesticate and ratify all international and regional frameworks;

2) Develop gender implementation plans and policies;

3) Design gender monitoring and impact assessment machineries with women as members;

4) Capacity building of gender policy implementation, monitoring and evaluation frameworks at the national, state and local government levels;

5) Involve civil society organization in all legal, policy and program empowerment machineries for women;

6) Creative cultural and legal reforms to remove discriminatory and disempowerment practices against women in Africa 
with the involvement of patriarchal chiefs and village women groups;

7) Cultural re-education and public awareness of issues affecting women;

8) Generation of gender sensitive and responsive data through the application of gender disaggregated data to enhance the full inclusion of gender issues in the development process;

9) Direct empowerment of women in the policy making and implementation process at the village, local, state and national governments;

10) Establishment of Gender Courts to try violations of gender legislative mechanisms;

11) Establishment of Gender Ministries to integrate, quicken and document all gender related policies and programs in every country in Africa.

If these proactive measures and programs are taken they will empower women and redress gender inequality in a manner that will help the Continent to achieve sustainable development in a post 2015 era for all mankind. These measures are sustainable since they follow from the thesis of this paper that ending inequality is an empowerment issue; and that genuine empowerment is a gender issue that gives voice and participatory ability for women, personally and collectively, at every level of decision making in African governance. Empowerment is also something that is attitudinal, that requires women to be re-oriented to believe in themselves and for the men to change their enslaving and discriminatory attitudes against women. It has to do with a transformational change of mindset for both genders in Africa partnering together to achieve the transformation of Africa. African men and women working together to end dis-empowerment structures, attitudes, relationships, cultures and policies require a paradigm shift in the African cultural bar that will foster change in all the dimensions and areas of development that currently challenges Africa. For that process to take place, African women needed to be empowered at the levels of personal, collective and associational framework of relationship with men in the real terms to take part in the decision making programming that affects their lives and the entire society.

\section{REFERENCES}

Abu-Ghaida, D., \& Klasen, S. (2004). The costs of missing the millennium development goal on gender equality. World Development, 32, 1075-1107. http://dx.doi.org/10.1016/j.worlddev.2004.02.003

Akinyi-Nzioki, E. (2006). Land policies in Sub-Saharan Africa. Center for Land, Economy and Rights of Women, Kul Graphics, Nairobi.

Ani, C. K. C. (2013). The church and gender equality in Africa: Questioning culture and the theological paradigm on women oppression. Open Journal of Philosophy, 2.

APR Secretariat and Government of Uganda (2008) Republic of Uganda African Peer Review Report, Midrand. Co AUC. African Union Draft Gender policy, Addis Ababa.

Awumbilla, M. (2004). African gender development index. Ghana Country Report.

Ballington, J. (2004). The implementation of quotas: African experiences. Institute for Democracy and Electoral Assistance, Stockholm.

Budlender D., Hicks J., \& Vetten, L. (2002) South Africa: Expanding into diverse initiatives. In D. Budlender, \& G. Hewitt (Eds.), Gender budgets make more cents country studies and good practice. London: Commonwealth Secretariat.

Government of Kenya (2005). MDG status report for Kenya. Nairobi.

Government of Malawi (2004). State Party report of Malawi to the CEDAW Committee. Lilongwe.

Government of Sierra Leone (2004). PRSP of Sierra Leone, a national programme for food security. Job Creation and Good Governance
(2005-2007), Freetown.

Government of Tanzania (2004). Party report of Togo to the CEDAW Committee.

Government of Togo (2004). State Party report of Togo to the CEDAW Committee.

Green Africa Network (2004). Policy document on overall sustainable women development for socioeconomic development of rural Africa, Nairobi.

IFAD (1999). The issue of poverty among female headed households in Africa. Rome.

ILO (2006). Key indicators of the labour market version 5 CD-ROM. Geneva.

ILO (2008). Global employment trends for women. Geneva.

Longwe, S. H. (2000). Towards realistic strategies for women's political empowerment in Africa. Gender and Development, 8, 24-30. http://dx.doi.org/10.1080/741923784

Madu, A. C. (2010). Women empowerment: Its relation to national development and human rights. Enugu: Snaap Press.

McWhirter (1991). Meta-ethics normative ethics. Philosophy of gender, race, and sexuality. Texas University Monograph on Philosophy of Law, 222-227.

OECD and NEPAD (2007). Gender and economic empowerment in Africa outcome. The Meeting of the 8th Africa partnership forum, Berlin, 22-23 May 2007.

Oxfam (2004). Mozambique's family law passes. http://www.oxfam.org/en/programs/development/safrica/moz_law.ht $\mathrm{m}$

Reeves, H., \& Baden, S. (2000). Gender and development: Concepts and definitions. Report prepared for the Department for International Development (DFID) for its gender mainstreaming intranet resource, Institute of Development Studies, BRIDGE report Number 55, Brighton.

Rowlands, J. (1997). Questioning empowerment. Working women in Honduras. Oxfam, Dublin.

UN INSTRAW (2011). Gender mainstreaming guide, glossary of gender-related terms and concepts. http://www.uninstraw.org/en/index

UNDAW (2005). Enhancing participation of women in development through an enabling environment for achieving gender equality and the advancement of women. Aide Memoire, Bangkok, 8-11 November 2005.

UNDAW and IPU (2008). Women in politics, Situation as at 1st January 2008, New York.

UNECA (2004a). The African gender and development index. (ECA) Addis Ababa.

UNECA (2004b). 7th African Regional Conference on Women (Beijing +10) Decade Review of the Implementation of the Dakar and Beijing Platforms of Action: Outcome and Way forward, Addis Ababa.

UNECA (2005a). Economic report on Africa 2005. Meeting the Challenges of Unemployment and Poverty in Africa. Addis Ababa.

UNECA (2005b). Promoting gender equality and women's empowerment in Africa: Questioning the achievements and confronting the challenges ten years after Beijing. Addis Ababa.

UNECA (2006). Meeting the challenge of employment in Africa. An Issues Paper for the 25th meeting of the Committee of Experts of the Conference of African Ministers of Finance, Planning and Economic Development, Ouagadougou, 10-13 May 2006.

UNECA (2007a). Accelerating Africa's growth and development to meet the MDGs: Emerging challenges and the way forward. An Issues Paper for the Conference of African Ministers of Finance, Planning and Economic Development/40th session of the Commission 26th Meeting of the Committee of Experts, Addis Ababa, 29 March1 April 2007.

UNECA (2007b). Ministerial statement of the Conference of African Ministers of Finance, Planning and Economic Development/40th Session of the Commission 26th Meeting of the Committee of Experts, Addis Ababa, 29 March-1 April 2007.

UNECA (2007c). Millennium development goals report. Report to the Conference of Ministers of African Ministers responsible for Finance, Planning, and Economic Development held in Addis Ababa, April 2007.

UNECA (2007d). Land policy in Africa: A framework to strengthen 
land rights, enhance productivity and secure livelihoods. Addis Ababa.

UNECA (2008a). The millennium development goals in Africa: Progress and challenges.

UNECA (2008b). Millennium development goals monitoring: Challenges and opportunities for African countries-E/ECA/STATCOM/ 1/6. Report prepared for the First Meeting of the Statistical Commission for Africa (STATCOM-AFRICA I) held in Addis Ababa, 21-24 January 2008.

UNECA (Forthcoming). African Women's Report, Addis Ababa.

UNECA and AUC (Forthcoming). Good practices for addressing GBV/ VAW in Africa, Draft Document, September 2008, Addis Ababa.

UNECA-NA (2005). The economic participation of women in North Africa, Rabat.

UNECA-SA (2003). Land tenure systems and sustainable development in Southern Africa, Lusaka.

UNESCO (2003). UNESCO's gender mainstreaming implementation framework: Baseline definitions of key concepts and terms. http://portal.unesco.org/es/files/11483/10649049699Definitions.doc/ Definitions.doc
WHO (2002). Gender and reproductive rights glossary. Geneva: World Health Organization.

http://www.who.int/reproductive-health/gender/glossary.html

WHO (2006). The health of the people: The African regional health report. Geneva: WHO.

WHO (2007). Maternal mortality in 2005: Estimates developed by WHO, UNICEF, UNFPA and the WorldBank, WHO, Geneva.

Women Empowerment framework Forum (CEPPER) (2012). The Centre For Peace-building and Poverty Reduction (CEPPER), chaired by Dr Ani Casimir, organized the women empowerment framework forum, (WEFRAF), for university women and gender rights lecturers/activists in the South Eastern Nigeria to assess the level of empowerment attained by women in the cultural zone and to identify obstacles to the empowerment of women in Africa.

World Bank (2000). Can Africa claim the 21st century? The World Bank, Washington DC.

World Bank (2001). Engendering development: Through gender equality in rights, resources, and voice. World Bank Research Report, Washington DC. 